\title{
A randomised trial of domiciliary, ambulatory oxygen in patients with COPD and dyspnoea but without resting hypoxaemia
}

\author{
Rosemary P Moore, 1,2,3,4,5 David J Berlowitz, ${ }^{1,2,3,4,5}$ Linda Denehy, ${ }^{4}$ Jeffrey J Pretto, ${ }^{1,6}$ \\ Danny J Brazzale, ${ }^{1,2}$ Ken Sharpe, ${ }^{7}$ Bruce Jackson, ${ }^{8}$ Christine F McDonald ${ }^{1,2,5}$
}

${ }^{1}$ Institute for Breathing and Sleep, Austin Hospital, Heidelberg, Victoria, Australia ${ }^{2}$ Department of Respiratory and Sleep Medicine, Austin Hospital, Heidelberg, Victoria, Australia

${ }^{3}$ The Northern Clinical Research Centre, The Northern Hospital, Epping, Victoria, Australia ${ }^{4}$ Melbourne Physiotherapy School, The University of Melbourne, Parkville, Victoria, Australia

${ }^{5}$ Melbourne Medical School, The University of Melbourne, Parkville, Victoria, Australia ${ }^{6}$ Department of Respiratory and Sleep Medicine, John Hunter Hospital, Newcastle, New South Wales, Australia ${ }^{7}$ Department of Mathematics and Statistics, The University of Melbourne, Victoria, Australia ${ }^{8}$ Vascular Medicine Unit, Dandenong Hospital, Dandenong, Victoria, Australia

\section{Correspondence to}

Professor Christine F McDonald, Department of Respiratory and Sleep Medicine, Level One Harold Stokes Building, Austin Hospital, Studley Road, Heidelberg, Victoria 3084, Australia;

christine.mcdonald@austin.org. au

Received 2 December 2009 Accepted 15 June 2010 Published Online First 29 September 2010

\begin{abstract}
Background Patients with chronic obstructive pulmonary disease (COPD) who are not severely hypoxaemic at rest may experience significant breathlessness on exertion, and ambulatory oxygen is often prescribed in this circumstance despite a lack of conclusive evidence for benefit. This study aimed to determine whether such patients benefit from domiciliary ambulatory oxygen and, if so, which factors may be associated with benefit.
\end{abstract}

Methods This was a 12 week, parallel, double-blinded, randomised, placebo-controlled trial of cylinder air versus cylinder oxygen, provided at $6 \mathrm{l} / \mathrm{min}$ intranasally, for use during any activity provoking breathlessness. Patients underwent baseline measurements of arterial blood gases and lung function. Outcome measures assessed dyspnoea, health-related quality of life, mood disturbance, functional status and cylinder utilisation. Data were analysed on an intention-to-treat basis, $\mathrm{p} \leq 0.05$.

Results 143 subjects (44 female), mean \pm SD age $71.8 \pm 9.8$ years, forced expiratory volume in $1 \mathrm{~s}\left(\mathrm{FEV}_{1}\right)$ $1.16 \pm 0.51$ lites, $\mathrm{PaO}_{2} 9.5 \pm 1.1 \mathrm{kPa}(71.4 \pm 8.5 \mathrm{~mm} \mathrm{Hg})$ were randomised, including 50 patients with exertional desaturation to $\leq 88 \%$. No significant differences in any outcome were found between groups receiving air or oxygen. Statistically significant but clinically small improvements in dyspnoea and depression were observed in the whole study group over the 12 weeks of the study.

Conclusion In breathless patients with COPD who do not have severe resting hypoxaemia, domiciliary ambulatory oxygen confers no benefits in terms of dyspnoea, quality of life or function. Exertional desaturation is not predictive of outcome. Intranasal gas (either air or oxygen) may provide a placebo benefit.

Clinical trial number ACTRN12605000457640.

\section{INTRODUCTION}

Chronic obstructive pulmonary disease (COPD) is a leading cause of disability and death globally, characterised by progressive breathlessness, loss of function and, in its later stages, chronic hypoxaemia. Correction of hypoxaemia with long-term continuous oxygen therapy increases life expectancy and is a mainstay of treatment. ${ }^{12}$

Many patients with COPD, without resting hypoxaemia, experience significant breathlessness on exertion and, in some cases, ambulatory oxygen is prescribed. Such prescription is usually contingent upon demonstration of both relief of exertional desaturation and symptomatic benefit during a laboratory-based test. However, improvements in exercise capacity and dyspnoea with supplemental oxygen may also be observed in patients who do not desaturate on exertion ${ }^{3} 4$ and are hypothesised to result from reduced dynamic hyperinflation. ${ }^{5} 6$

Although studies in the clinic or laboratory setting have demonstrated modest increments in exercise capacity with supplemental oxygen, the use of domiciliary ambulatory oxygen is not strongly evidence based. ${ }^{7}$ Studies designed to examine its use have conflicting findings and are limited by small sample sizes. ${ }^{8-13}$ Lilker et al reported no change in dyspnoea, subjective assessment of activity or distance walked per day in nine patients with resting hypoxaemia randomised to air or oxygen in a 10 week crossover study, ${ }^{8}$ and Lacasse et al reported no impact on health-related quality of life (HRQoL) or exercise tolerance in a study comparing additional ambulatory air or oxygen in patients on long-term continuous oxygen therapy. ${ }^{9}$ Nonoyama et al reported no improvement in HRQoL after ambulatory oxygen compared with air in 27 patients with exertional desaturation over three pairs of 2 week treatments. ${ }^{10}$ Sandland and colleagues demonstrated no improvements over 8 weeks in physical activity levels, HRQoL or time away from home with oxygen versus air in 20 patients following completion of pulmonary rehabilitation. ${ }^{11}$

McDonald et al examined 26 patients, some with exertional desaturation, in a 6 week crossover trial of ambulatory air and oxygen, and found a statistically significant but clinically small improvement in exercise capacity after oxygen compared with air but no difference in HRQoL. ${ }^{12}$ In contrast, in a study of 41 patients with COPD and exertional desaturation, Eaton et al reported no difference in exercise capacity or dyspnoea after oxygen compared with air, but statistically significant, albeit clinically small, improvements in HROoL, anxiety and depression. ${ }^{13}$

Given the limitations and differing results of these previous studies, our aim was to perform a large, adequately powered study to determine the effects of domiciliary ambulatory oxygen in patients with COPD and exertional dyspnoea, without severe resting hypoxaemia; with or without exercise desaturation. The primary outcome measure was dyspnoea. Secondary outcomes were HRQoL, mood disturbance, functional status and gas utilisation. A further aim was to identify factors which might predict any observed benefit. 


\section{METHODS}

\section{Design}

Following research ethics approval this prospective, parallel, double-blinded, randomised controlled trial recruited patients with COPD and assigned them randomly to cylinder air or cylinder oxygen using a computer-generated sequence and concealed allocation. Study personnel and participants were blinded to group allocation. Cylinders were of identical appearance, weighed $4.2 \mathrm{~kg}$ filled, were provided with a trolley/stroller and delivered gas at a flow rate of $61 / \mathrm{min}$ via the Impulse Elite conservation device (AirSep Corporation, Buffalo, New York, USA). Verbal and written instructions required patients to use cylinders inside and outside the home during exertional activities that induced breathlessness. No recommendations were provided regarding duration of use, activity or exercise. Written instructions were provided regarding cylinder use and replacement procedures.

\section{Participants}

Clinically stable ex-smokers with COPD on optimal medical treatment, having $\mathrm{PaO}_{2}>7.3 \mathrm{kPa}$ at rest breathing room air and moderate to severe exertional dyspnoea (Medical Research Council Dyspnoea Scale grade $\geq 3^{14}$ ), were recruited through database screening and advertisement. Exclusion criteria were current participation in a Pulmonary Rehabilitation Programme, current domiciliary oxygen use, significant communication or locomotor difficulties, or other severe medical conditions. Patients with $\mathrm{PaCO}_{2}>6.0 \mathrm{kPa}$ underwent repeat arterial blood gas analysis after breathing oxygen at $6 \mathrm{l} / \mathrm{min}$, at rest, for $30 \mathrm{~min}$, and were excluded if $\mathrm{PaCO}_{2}$ increased by more than $0.7 \mathrm{kPa}$.

\section{Procedures}

Arterial blood gases, pulmonary function tests and dyspnoea rating on both the Baseline Dyspnoea Index and the Medical Research Council scales were measured at trial entry only. Pulmonary function tests were performed according to American Thoracic Society guidelines ${ }^{15}{ }^{16}$ using the SensorMedics Vmax Series Lung Function System (SensorMedics Corporation, Yorba Linda, California, USA), and validated predicted values for spirometry, ${ }^{17}$ transfer factor ${ }^{18}$ and thoracic gas volumes. ${ }^{19}$ Volume response to hyperoxia was determined by measuring the difference between resting inspiratory capacity breathing $21 \%$ oxygen and $44 \%$ oxygen. ${ }^{20}$

Following a 2 week run-in period to confirm clinical stability, all other assessments were performed prior to randomisation. This test battery was repeated 4 weeks (mid-trial) and 12 weeks later (end-study). Dyspnoea was assessed using the dyspnoea domain of the Chronic Respiratory Disease Questionnaire $(\mathrm{CRDO})^{21}$ and the Baseline/Transition Dyspnoea Index (BDI/ TDI). ${ }^{22}$ HRQoL was examined using the CRDQ total score ${ }^{21}$ and the Assessment of Quality of Life Utility Index (AQoL) ${ }^{23}$ and mood disturbance using the Hospital Anxiety and Depression Scale (HADS). ${ }^{24}$ Functional capacity was measured using standardised tests of 6 min walk distance (6MWD) breathing cylinder air in a single-blinded manner. ${ }^{25}$ Functional performance was measured objectively using the activity count from a waist-mounted pedometer (Yamax Digiwalker, model SW-700, Yamax Corporation, Tokyo, Japan) and subjectively from diaryreported time spent outside the home and time spent standing or walking. ${ }^{26}$ Gas utilisation was expressed as number of cylinders used (calculated from gas pressure in returned cylinders) and as hours of use from self-reported diary data.

\section{Sample size}

Power calculations determined that 154 participants were required to provide a power of 0.8 , at an $\alpha$ level of 0.05 , to detect the minimal important difference (MID) in the primary outcome measure, the dyspnoea domain of the CRDQ, of 2.5 units, ${ }^{27}$ allowing for $20 \%$ attrition. Sample sizes of 142 and 130 participants, respectively, were determined to be required with regard to CRDQ total score (MID of 10 units $^{27}$ ) and $6 \mathrm{MWD}$ (MID of $54 \mathrm{~m}^{28}$ ).

\section{Analyses}

Level of statistical significance was set at $p \leq 0.05$. Demographic data were compared using $\chi^{2}$ or $t$ tests. Intention-to-treat analyses were performed. TDI scores and cylinder utilisation data were analysed using $t$ tests to compare treatment means at weeks 4 and 12 postrandomisation. Other outcome measures were analysed using two-way, repeated measure analysis of variance, with treatment allocation and time as the two explanatory variables.

Variables selected a priori to identify subgroups which might benefit differentially from domiciliary ambulatory oxygen were exertional desaturation, ${ }^{25}$ severity of airflow obstruction, gender, severity of dyspnoea, ${ }^{29}$ and volume ${ }^{5}$ or exercise ${ }^{28}$ response to hyperoxia. Data were analysed using analysis of covariance (ANCOVA), with week 12 values as the response variable, the corresponding value at baseline as the covariate and each of the subgroup variables as an explanatory factor, in addition to treatment (air or oxygen). All ANCOVA models initially included an interaction term between the subgroup variable and the treatment, but these were omitted if found to be not statistically significant $(p>0.05)$. In most cases the analysis was repeated after a small number of extreme outliers was omitted. Omission of the outliers did not change the outcome of the test $(p \leq 0.05$ or $p>0.05)$. and only the results with the outliers omitted are presented.

\section{RESULTS}

Of 160 patients enrolled, 143 (44 females) proceeded to randomisation and 139 completed the study (figure 1). Patients had moderate to severe COPD $\left(\mathrm{FEV}_{1}\right.$ mean \pm SD $1.16 \pm 0.51$ litres). With the exception of a statistically significant but clinically small difference in transfer factor, there were no significant differences between air and oxygen groups at baseline (table 1). Exertional desaturation was demonstrated in $35 \%$ of participants (table 1). At baseline, there was a statistically significant but clinically trivial acute improvement in $6 \mathrm{MWD}$ for the group as a whole when breathing cylinder oxygen (mean increase $\pm \mathrm{SD}$, compared with $6 \mathrm{MWD}$ using cylinder air, $10.7 \pm 38.7 \mathrm{~m}$, $\mathrm{p}=0.001)$. This increase was not significantly greater for the subgroup of desaturators as a whole $(13.8 \pm 28.4 \mathrm{~m}, \mathrm{p}<0.001)$, compared with the total group ( $\mathrm{p}=0.596$ ).

Data are presented as mean (SD) for all variables except exertional desaturation, where number (percentage) of cases within each group is reported. Similarly, observed $p$ values for $t$ tests comparing group means are reported for all variables except exertional desaturation where the $\chi^{2}$ comparing proportions is presented. Exertional desaturation was defined as $\mathrm{SpO}_{2} \leq 88 \%$ at the end of a 6 min walk test (6MWT) breathing cylinder air.

No significant differences were found between air and oxygen groups for CRDO dyspnoea (figure 2), HRQoL or the functional outcome measures over the time of the study (tables 2 and 3). There were no differences between groups for TDI scores at either week 4 or week 12 ( $p=0.5$ and 0.7 , respectively). 
Figure 1 Flow diagram showing the number of subjects screened, enrolled and who completed the study.

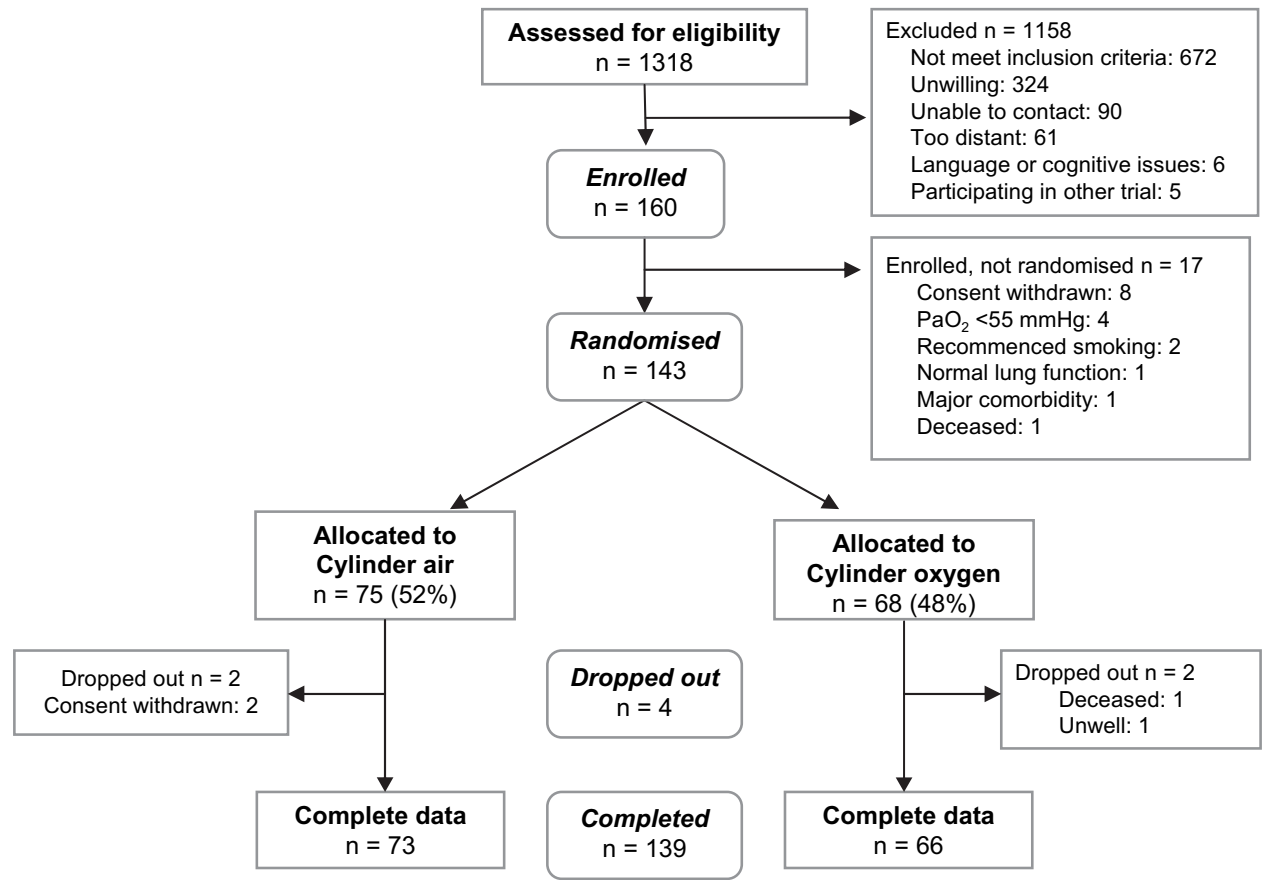

In participants overall, statistically significant improvements (mean, 95\% CIs) were found over the study period for CRDO dyspnoea scores (1.3, 0.6 to 2.1) and HADS depression scores $(0.6,1.0$ to 0.2$)$. The TDI demonstrated no significant change in dyspnoea in participants overall at week $4(0.4,0.1$ to 0.6$)$ or week $12(0.3,-0.1$ to 0.6$)$.

The mean $\pm \mathrm{SD}$ number of cylinders used over 12 weeks was $8.0 \pm 8.9$, and $82.6 \%$ of participants used $\leq 12$ cylinders. There were no significant differences between air and oxygen groups for mean number of cylinders used (air group 7.2, oxygen group 8.9, $\mathrm{p}=0.245)$ or for self-reported hours of use at week 4 $(p=0.445)$ or at week $12(p=0.697)$. A survey of participants at study completion found that $46 \%$ of the oxygen group and $45 \%$ of the air group would have preferred to cease using cylinders altogether, and an additional three (air group) were undecided $(p=0.254)$. Only 38 participants $(28 \%)$ reported that their cylinders helped their breathing, and 62 (50\%) reported

Table 1 Demographic data for treatment groups

\begin{tabular}{|c|c|c|c|}
\hline & $\begin{array}{l}\text { Air } n=75 \\
(52 \%)\end{array}$ & $\begin{array}{l}\text { Oxygen } \\
n=68(48 \%)\end{array}$ & p Value \\
\hline Age (years) & $72(10.4)$ & $72(9.2)$ & 0.90 \\
\hline $\mathrm{FEV}_{1}$ (litres) & $1.17(0.5)$ & $1.15(0.5)$ & 0.84 \\
\hline $\mathrm{FEV}_{1} \%$ predicted & 47 (19.5) & $47(18.3)$ & 0.98 \\
\hline FVC (litres) & $2.59(0.8)$ & $2.60(0.9)$ & 0.93 \\
\hline FVC \% predicted & 79 (18.7) & $80(22.9)$ & 0.79 \\
\hline $\mathrm{FEV}_{1} / \mathrm{FVC}^{2} \%$ & $42(13.7)$ & $40(12.5)$ & 0.40 \\
\hline TLCO (ml/min/mm Hg) & $11.0(4.0)$ & $12.3(4.3)$ & 0.07 \\
\hline TLCO \% predicted & $44(13.6)$ & $49(14.6)$ & 0.02 \\
\hline IC (litres) & $1.8(0.6)$ & $1.9(0.6)$ & 0.68 \\
\hline IC \% predicted & $83(23.2)$ & $86(20.4)$ & 0.35 \\
\hline BMI $\left(\mathrm{kg} / \mathrm{m}^{2}\right)$ & $26.3(6.5)$ & $27.7(5.8)$ & 0.15 \\
\hline $\mathrm{PaO}_{2}$ & $70.0(8.4)$ & $72.6(8.9)$ & 0.08 \\
\hline $\mathrm{PaCO}_{2}$ & $40.3(4.7)$ & $40.7(5.3)$ & 0.63 \\
\hline BDI focal score & $3.4(1.7)$ & $3.5(2.0)$ & 0.80 \\
\hline Exertional desaturation & $29(39 \%)$ & $21(31 \%)$ & 0.26 \\
\hline
\end{tabular}

BDI, Baseline Dyspnoea Index; BMI, body mass index; $\mathrm{FEV}_{1}$, forced expiratory volume in 1 s; FVC, forced vital capacity; IC, inspiratory capacity; TLCO, diffusing capacity of the lungs for carbon monoxide. difficulties with the apparatus including poor portability and difficulty changing the regulator.

Although no overall differences were observed between the air and oxygen groups, analyses were performed to examine whether participants with particular baseline characteristics may have been more sensitive to any benefit from oxygen. These analyses, summarised in table 4 , showed that any improvement in the dyspnoea domain of the CRDO that may have been attributable to oxygen was not predicted by exertional desaturation, severity of airflow obstruction or dyspnoea, volume or exercise response to hyperoxia or gender ( $p>0.05$ in all cases) (table 4).

The secondary outcome measures, CRDQ total score, outings time, pedometer count, stand/walk time, 6MWD on cylinder air, AQoL Utility Index, HADS-anxiety and HADS-depression scores were similarly analysed. From the 64 such analyses carried out, a statistically significant interaction between the treatment and one of the subgroup factors was observed in four cases. These

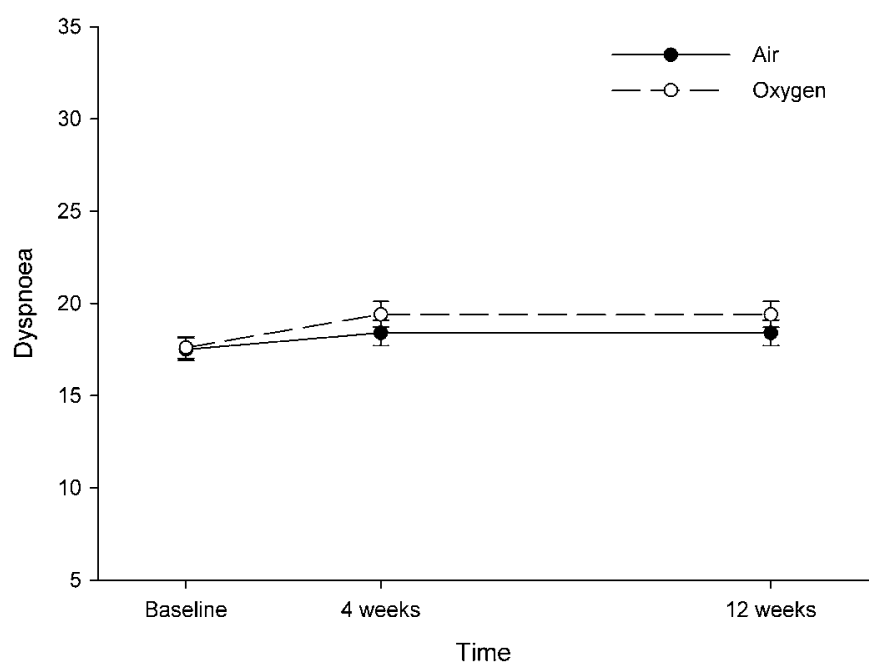

Figure 2 Effect of treatment on dyspnoea. 
Table 2 Quality of life and mood outcomes

\begin{tabular}{|c|c|c|c|c|c|c|c|}
\hline & & \multirow{2}{*}{$\begin{array}{l}\text { Time } \\
\text { (weeks) }\end{array}$} & \multirow{2}{*}{$\begin{array}{l}\text { Air mean } \\
\text { (SD) }\end{array}$} & \multirow{2}{*}{$\begin{array}{l}\text { Oxygen } \\
\text { mean (SD) }\end{array}$} & \multicolumn{3}{|c|}{ ANOVA: $p$ Values } \\
\hline & & & & & Treatment & Time & Interaction \\
\hline \multirow[t]{11}{*}{$\mathrm{CRDO}^{*}$} & Dyspnoea & Baseline & $17.5(4.9)$ & $17.6(5.2)$ & 0.439 & $<0.001$ & 0.843 \\
\hline & Range: $5-35$ & 4 & $18.4(5.8)$ & $19.7(5.4)$ & & & \\
\hline & MID: 2.5 & 12 & $18.4(5.9)$ & $19.5(6.0)$ & & & \\
\hline & Fatigue & Baseline & $15.2(4.1)$ & $15.3(5.0)$ & 0.846 & 0.076 & 0.837 \\
\hline & Range: $4-28$ & 4 & $15.9(4.8)$ & $16.1(5.3)$ & & & \\
\hline & Range: $7-49$ & 4 & $34.0(7.5)$ & $35.6(8.6)$ & & & \\
\hline & MID: 3.5 & 12 & $34.3(8.2)$ & $34.5(9.7)$ & & & \\
\hline & Mastery & Baseline & $19.7(4.5)$ & $19.7(4.7)$ & 0.585 & 0.696 & 0.436 \\
\hline & Range: $4-28$ & 4 & $19.4(4.8)$ & $20.6(4.6)$ & & & \\
\hline & MID: 2.0 & 12 & $19.8(5.4)$ & $20.2(5.2)$ & & & \\
\hline & Total score & Baseline & $86.3(16.6)$ & 87.7 (18.4) & 0.596 & 0.054 & 0.912 \\
\hline$A 0 L^{*}$ & MID: 0.06 & 12 & $0.57(0.27)$ & $0.52(0.27)$ & & & \\
\hline \multirow[t]{6}{*}{ HADS $†$} & Anxiety & Baseline & $5.7(4.1)$ & $5.3(4.2)$ & $0.678 \neq$ & 0.083 & 0.970 \\
\hline & Range: $0-21$ & 4 & $5.4(3.7)$ & $5.1(4.3)$ & & & \\
\hline & & 12 & $5.4(3.9)$ & $5.4(4.6)$ & & & \\
\hline & Depression & Baseline & $5.4(2.8)$ & $5.8(3.6)$ & 0.981 & $<0.001$ & 0.203 \\
\hline & Range: $0-21$ & 4 & $5.1(3.0)$ & $4.9(3.4)$ & & & \\
\hline & & 12 & $5.1(3.4)$ & $4.9(3.5)$ & & & \\
\hline
\end{tabular}

*Higher scores represent better quality of life.

†Higher scores represent more anxiety or depression.

$\ddagger A N O V A$ used square-root transformation.

ANOVA, analysis of variance; AQoL, Assessment of Quality of Life questionnaire; CRDQ, Chronic Respiratory Disease Questionnaire; HADS, Hospital Anxiety and Depression Scale,

$\geq 10=$ clinically significant Anxiety and/or Depression; MID, minimal important difference; Range, highest and lowest scores able to be obtained on each of the tests.

were: interaction between treatment and severity of airflow obstruction $(p=0.016)$ and between treatment and exercise response to hyperoxia ( $p=0.027)$ for the (log-transformed) pedometer count, interaction between treatment and exercise response to hyperoxia for the (square-root transformed) HADSanxiety score $(p=0.003)$ and interaction between treatment and level of desaturation $(p=0.047)$ for the AQoL Utility Index.

\section{DISCUSSION}

This is the largest reported parallel, double-blinded, randomised controlled study of the effects of domiciliary ambulatory oxygen in patients with COPD and significant exertional breathlessness. Just over one-third of patients desaturated to $\leq 88 \%$ with exertion. Although, as in previous studies, there were small acute improvements in exercise capacity with oxygen compared with air during initial in-laboratory tests, these improvements fell far short of the 35-54 m, described as the MID for the $6 \mathrm{MWT} .^{28}{ }^{30}$ We found no improvement in dyspnoea, HRQoL, functional capacity or performance with domiciliary use of cylinder oxygen compared with cylinder air, no difference in gas usage between groups and no factors which were predictive of benefit in any subgroup overall.

We observed statistically significant improvements in CRDO dyspnoea score and depression in participants during the study regardless of which gas they received. These changes were less than those accepted to be of clinical importance and are similar

Table 3 Functional capacity and performance outcomes

\begin{tabular}{|c|c|c|c|c|c|c|}
\hline & \multirow{2}{*}{$\begin{array}{l}\text { Time } \\
\text { (weeks) }\end{array}$} & \multirow{2}{*}{$\begin{array}{l}\text { Air mean } \\
\text { (SD) }\end{array}$} & \multirow{2}{*}{$\begin{array}{l}\text { Oxygen } \\
\text { mean (SD) }\end{array}$} & \multicolumn{3}{|c|}{ ANOVA: $p$ Values } \\
\hline & & & & Treatment & Time & Interaction \\
\hline \multirow[t]{3}{*}{ 6MWD (m) } & Baseline & 341 (88.9) & 341 (93.2) & 0.843 & 0.055 & 0.685 \\
\hline & 4 & 359 (95.9) & 348 (99.9) & & & \\
\hline & 12 & $357(100.0)$ & $352(114.0)$ & & & \\
\hline \multirow[t]{3}{*}{ Stand/walk time (h/week) } & Baseline & $3.7(15.2)$ & $38.7(15.2)$ & 0.341 & 0.325 & 0.344 \\
\hline & 4 & $37.8(14.7)$ & $38.8(15.7)$ & & & \\
\hline & 12 & $36.7(15.5)$ & $40.2(16.0)$ & & & \\
\hline \multirow[t]{3}{*}{ Outings time (h/week) } & Baseline & $15.9(10.4)$ & $19.2(12.4)$ & $0.197^{*}$ & 0.570 & 0.305 \\
\hline & 4 & $15.3(10.1)$ & $19.1(13.9)$ & & & \\
\hline & 12 & $16.4(11.2)$ & $17.6(12.8)$ & & & \\
\hline \multirow[t]{3}{*}{ Pedometer count (steps/week) } & Baseline & $23491(18549)$ & $24144(19946)$ & $0.462 \dagger$ & 0.473 & 0.162 \\
\hline & 4 & $23877(18591)$ & $24613(20522)$ & & & \\
\hline & 12 & $23638(18442)$ & $28002(22387)$ & & & \\
\hline
\end{tabular}

Community activity was measured subjectively (diary record of time spent standing or walking and on outings per week) and objectively (pedometer count of steps taken per week). 
Table 4 Baseline variables which were examined to determine if there was a differential benefit from ambulatory oxygen compared with ambulatory air

\begin{tabular}{|c|c|c|c|c|c|c|}
\hline \multirow[b]{2}{*}{ (Subgroup) Variable } & \multirow[b]{2}{*}{ Subgroups } & \multicolumn{3}{|c|}{ P Values } & \multicolumn{2}{|c|}{ Oxygen-air } \\
\hline & & $\mathbf{T} \times \mathbf{V}^{*}$ & $\mathbf{v} †$ & $\mathbf{T} \neq$ & Estimate§ & $95 \% \mathrm{Cl}$ \\
\hline None & & & & 0.312 & 0.775 & $(-0.736$ to 2.285$)$ \\
\hline Desaturation & $\mathrm{No}^{* *}$ & 0.393 & 0.706 & 0.336 & 0.744 & $(-0.780$ to 2.268$)$ \\
\hline$n=138$ & Yes & & & & & \\
\hline Severity of airflow obstruction & $\mathrm{FEV}_{1} \%<50$ & 0.838 & 0.332 & 0.378 & 0.681 & $(-0.841$ to 2.203$)$ \\
\hline$n=138 † \dagger$ & $50-69 \geq 70$ & & & & & \\
\hline $\begin{array}{l}\text { Exercise response to oxygen } \\
n=127\end{array}$ & $\begin{array}{l}6 \mathrm{MWD} \ddagger \neq<54 \mathrm{~m} \\
\geq 54 \mathrm{~m}\end{array}$ & 0.768 & 0.562 & 0.168 & 1.126 & $(-0.480$ to 2.731$)$ \\
\hline $\begin{array}{l}\text { Volume response to hyperoxia } \\
n=137\end{array}$ & $\begin{array}{l}\Delta \mathrm{IC} \S<<10 \% \\
\geq 10 \%\end{array}$ & 0.224 & 0.115 & 0.247 & 0.887 & $(-0.621$ to 2.395$)$ \\
\hline Severe breathlessness & BDI score $₫ \Phi \leq 4$ & 0.153 & 0.759 & 0.355 & 0.715 & $(-0.809$ to 2.238$)$ \\
\hline$n=137$ & $>4$ & & & & & \\
\hline Gender & Female & 0.317 & 0.442 & 0.338 & 0.738 & $(-0.778$ to 2.254$)$ \\
\hline$n=138$ & Male & & & & & \\
\hline $\begin{array}{l}\text { All of the above; main effects only } \\
n=125\end{array}$ & & & $\geq 0.171$ & 0.201 & 1.075 & $(-0.581$ to 2.730$)$ \\
\hline
\end{tabular}

Data represent the analysis of covariance results, with week 12 values as the response variable, the corresponding value at baseline as the covariate and each of the subgroup variables as an explanatory factor, in addition to treatment (air or oxygen).

*Treatment (oxygen or air) by (subgroup) variable interaction.

†(Subgroup) variable.

‡Treatment: oxygen or air.

$\S$ Estimate of the mean difference in dyspnoea scores between subjects on oxygen and those on air, after allowing for dyspnoea scores at baseline (as a covariate) and the (subgroup) variable. T95\% $\mathrm{Cl}$ associated with the estimate (in previous column).

${ }^{*} \mathrm{SpO}_{2}$ at the conclusion of a 6 min walk test breathing air. $\mathrm{No}=\mathrm{SpO}_{2}>88 \%, \mathrm{Yes}=\mathrm{SpO}_{2} \leq 88 \%$.

††Sample size used for the analysis; one extreme outlier was omitted from all analyses while the level of the (subgroup) variable was unknown in some cases.

$\neq \ddagger$ Increase in 6 min walk distance (6MWD) breathing $6 \mathrm{l} / \mathrm{min} \mathrm{O}_{2}$ compared with air beyond the reported minimally important difference.

$\S \S$ Increase in percentage predicted inspiratory capacity $(\Delta I C)$ while breathing $44 \%$ oxygen compared with $21 \%$ oxygen.

-Dyspnoea dichotomised as severe or not according to the Baseline Dyspnoea Index (BDI) focal score.

$\mathrm{FEV}_{1}$, forced expiratory volume in $1 \mathrm{~s}$.

to those reported by Nonoyama et al. ${ }^{10}$ They suggest either a benefit from nasal gas insufflation, regardless of whether it is with air or oxygen, or a placebo effect.

Four of the ANCOVA results in the current study suggested an interaction between baseline factors and treatment. However, three of these results lack biological plausibility. Participants who had more severe airflow limitation performed worse with oxygen, and those able to increase their 6MWD with oxygen at baseline had a lower pedometer count and were more anxious when randomised to receive oxygen during the study. In contrast, the significant interaction between treatment and baseline exertional desaturation for the AQoL Utility Index suggested a potential benefit in the subgroup of 'desaturators' randomised to oxygen. Although this last result is consistent with the findings of a previous study, ${ }^{13}$ no main effect for treatment or subgroup was observed for any of the analyses of the CRDO dyspnoea score, the primary outcome of the study (tables 2 and 4). Additionally, all other domains of the CRDO and the CRDQ total score, a disease-specific HRQoL measure, showed no benefit from oxygen. Analysis of the results of the current study did not include any correction for multiple testing and thus the statistically significant interactions should be interpreted with caution.

The mean use of eight cylinders over 12 weeks represents an average of $40 \mathrm{~min}$ of gas use per day, which is comparable with that in previous studies where outcomes were remarkably consistent despite differences in apparatus used. ${ }^{8-10}$ Fifty per cent of participants reported difficulties with their apparatus, suggesting perhaps that any perceived benefits from using the gas were outweighed by negative factors relating to cylinder usage. Other reported barriers to use included fear of dependence (5 participants), embarrassment (5 participants) and an inability to change the regulator (5 participants).
The underlying mechanisms for dyspnoea and exercise limitation in COPD are complex, and improvements in exercise performance and dyspnoea with hyperoxia are probably multifactorial, relating to altered perception of dyspnoea, reduced ventilatory demand, improved respiratory and peripheral muscle function and possible cardiovascular effects. ${ }^{6}$ We chose dyspnoea rather than exertional desaturation as our main inclusion criterion in order to explore mechanisms other than relief of hypoxaemia which may explain improvements in dyspnoea with ambulatory oxygen. Our finding that exertional desaturation was not predictive of benefit is important given that this frequently forms the basis for ambulatory oxygen prescription, despite previous studies suggesting that the degree of exercise desaturation does not predict benefit. ${ }^{12} 31$ Our finding of a significant interaction between treatment and level of desaturation for the AQoL Utility Index may arguably temper the strength of our findings, but this may also represent a type 1 error. Importantly, no effect on disease-specific HROoL was observed. It remains possible that there may have been too few people in our subgroup of 'desaturators' to detect a benefit from ambulatory oxygen. However, this subpopulation of 50 subjects represents a greater number of 'desaturators' than were present in either of the two previous studies which specifically examined this question ${ }^{10}{ }^{13}$ and which also failed to show a convincing benefit from oxygen therapy.

Hyperoxia is believed to reduce dyspnoea during exercise by reducing ventilatory demand and delaying the onset of dynamic hyperinflation. Previous studies suggest that this may occur in a dose-dependent fashion, up to a fraction of inspired oxygen of 0.5 or a flow of $61 / \mathrm{min}$ of $100 \%$ oxygen. ${ }^{4}$ We chose a flow rate of $6 \mathrm{l} / \mathrm{min}$ in order to maximise this effect and because the lower flow rates used in previous studies may have provided inadequate relief from exercise-induced desaturation. ${ }^{8-10}$ 
Our study has limitations, some of which relate to all such studies using currently available portable or ambulatory apparatus. The filled cylinder weight of $4.2 \mathrm{~kg}$, which was necessary to ensure adequacy of oxygen supply using a flow rate of $61 /$ min, may have discouraged use in breathless patients, despite their being supplied with a trolley. Lighter weight systems might provide greater ease of carriage but have the disadvantage of requiring more frequent replacement or filling. The high flow rate may have proved a disincentive to use through drying or discomfort at the nares; however, no patients complained specifically of this issue. Confining this study only to patients who desaturated may have yielded different results. However, this seems unlikely given the similar negative results in studies by Nonoyama et $a l^{10}$ and to a lesser extent Eaton et al, ${ }^{13}$ both of which were confined to patients who desaturated with exertion, as well as the negative results in the study by Lacasse et al of even more severely hypoxaemic patients. ${ }^{9}$ Previous studies have demonstrated a lack of correlation between desaturation and acute benefit from supplemental oxygen and others have suggested alternative mechanisms for benefit from oxygen such as changes in operating lung volumes, hence our rationale for choosing breathlessness rather than desaturation as the criterion for entry to our study. We believe the results of the current study are applicable to breathless patients with COPD on maximal treatment, with or without exercise desaturation. They may not pertain to those with significant resting hypoxaemia fulfilling criteria for long-term oxygen therapy.

\section{CONCLUSION}

This randomised controlled trial found that domiciliary ambulatory oxygen provided no additional benefit over air in terms of dyspnoea, quality of life or function in patients with COPD experiencing exertional dyspnoea without severe resting hypoxaemia. Of six factors examined (gender, exertional desaturation, severity of airflow obstruction, severity of dyspnoea, volume or exercise response to hyperoxia), none was predictive of therapeutic benefit. Our findings do not support the use of domiciliary ambulatory oxygen as a treatment for dyspnoea in this group of patients and challenge the use of exertional desaturation as a primary criterion for its prescription. Our results were suggestive but not conclusive of placebo benefits from having domiciliary gas cylinders.

Acknowledgements The authors wish to acknowledge and thank Anthony D'Aloisio, Jeremy Friedman, Nadia Gagliardi, Chrissie Risteski and Sherine Yousef for their assistance.

Funding National Health and Medical Research Council, Northern Clinical Research Centre, Victorian Tuberculosis and Lung Association, Austin Hospital Medical Research Foundation, Institute for Breathing and Sleep, Austin Hospital, Australia Finkel Foundation, Air Liquide, Boehringer Ingelheim.

Competing interests None

Ethics approval This study was conducted with the approval of the Austin Hospital Medical Research Ethics Committee and the Northern Hospital Medical Research Ethics Committee.

Provenance and peer review Not commissioned; externally peer reviewed.

\section{REFERENCES}

1. Nocturnal Oxygen Therapy Trial Group. Continuous or nocturnal oxygen therapy in hypoxemic chronic obstructive lung disease: a clinical trial. Ann Intern Med 1980:93:391-8
2. Medical Research Council Working Party. Long term domiciliary oxygen therapy in chronic hypoxic cor pulmonale complicating chronic bronchitis and emphysema. Lancet 1981;:1:681-6.

3. O'Donnell D, Banzett R, Carrieri-Kohlman V, et al. Pathophysiology of dyspnea in chronic obstructive pulmonary disease. A roundtable. Proc Am Thorac Soc 2007:4:145-68.

4. Snider G. Enhancement of exercise performance in COPD patients by hyperoxia. Chest 2002;122:1830-6.

5. O'Donnell D, Laveneziana P. The clinical importance of dynamic lung hyperinflation in COPD. COPD 2006;3:219-32.

6. O'Donnell DE, D'Arsigny C, Webb KA. Effects of hyperoxia on ventilatory limitation during exercise in advanced chronic obstructive pulmonary disease. Am J Respir Crit Care Med 2001;163:892-8.

7. Bradley JM, Lasserson T, Elborn S, et al. A systematic review of randomized controlled trials examining the short-term benefit of ambulatory oxygen in COPD. Chest 2007;131:278-85.

8. Lilker E, Karnick A, Lerner L. Portable oxygen in chronic obstructive lung disease with hypoxemia and cor pulmonale: a controlled double-blind crossover study. Chest 1975;68:236-41

9. Lacasse $\mathbf{Y}$, Lecours $\mathrm{R}$, Pelletier $\mathrm{C}$, et al. Randomised trial of ambulatory oxygen in oxygen-dependent COPD. Eur Respir J 2005;25:1032-8.

10. Nonoyama M, Brooks D, Guyatt G, et al. Effect of oxygen on health quality of life in patients with chronic obstructive pulmonary disease with transient exertional hypoxemia. Am J Respir Crit Care Med 2007;176:343-9.

11. Sandland C, Morgan M, Singh S. Patterns of domestic activity and ambulatory oxygen usage in COPD. Chest 2008;134:753-60.

12. McDonald CF, Blyth CM, Lazarus MD, et al. Exertional oxygen of limited benefit in patients with chronic obstructive pulmonary disease and mild hypoxemia. Am J Respir Crit Care Med 1995;152:1616-19.

13. Eaton T, Garrett JE, Young P, et al. Ambulatory oxygen improves quality of life of COPD patients: a randomised controlled study. Eur Respir J 2002;20:306-12.

14. Bestall J, Paul E, Garrod R, et al. Usefulness of Medical Research Council (MRC) dyspnoea scale as a measure of disability in patients with chronic obstructive pulmonary disease. Thorax 1999;54:581-6.

15. American Thoracic Society. Standardization of spirometry. Am J Respir Crit Care Med 1995;152:1107-36.

16. American Thoracic Society. Single-breath carbon-monoxide diffusing capacity (transfer factor). Recommendations for a standard technique-1995 update. Am J Respir Crit Care Med 1995;152:2185-98.

17. Knudson R, Slatin R, Lebowitz M, et al. The maximal expiratory flow-volume curve: normal standards, variability and effects of age. Am Rev Respir Dis 1976;113:587-600.

18. Roca J, Rodriguez-Roisin R, Cobo E, et al. Single-breath carbon monoxide diffusing capacity prediction equations from a Mediterranean population. Am Rev Respir Dis 1990:141:1026-32.

19. Goldman H, Becklake M. Respiratory function tests; normal values at median altitudes and the prediction of normal results. Am Rev Tuberc 1959;79:457-67.

20. Moore R, Berlowitz D, Pretto J, et al. Acute effects of hyperoxia on resting pattern of ventilation and dyspnoea in COPD. Respirology 2009;14:545-50.

21. Guyatt G, Berman L, Townsend M, et al. A measure of quality of life for clinical trials in chronic lung disease. Thorax 1987;42:773-8.

22. Mahler D, Weinberg D, Wells $C$, et al. The measurement of dyspnoea. Contents, interobserver agreement, and physiologic correlates of two new clinical indices. Chest 1984;85:751-8.

23. Hawthorne G, Richardson J, Osborne R. The Assessment of Quality of Life (AOoL) instrument: a psychometric measure of health-related quality of life. Qual Life Res 1999;8:209-24.

24. Zigmund A, Snaith R. The hospital anxiety and depression scale. Acta Psychiatr Scand 1983;67:361-70.

25. American Thoracic Society. ATS statement: guidelines for the six-minute walk test. Am J Respir Crit Care Med 2002:166:111-17.

26. Moore R, Berlowitz D, Denehy L, et al. Comparison of pedometer and activity diary for measurement of physical activity in chronic obstructive pulmonary disease. J Cardiopulm Rehabil Prev 2009;29:57-61.

27. Jaeschke R, Singer J, Guyatt G. Measurement of health status. Ascertaining the minimal clinically important difference. Control Clin Trials 1989;10:407-15.

28. Redelmeier D, Bayoumi A, Goldstein R, et al. Interpreting small differences in functional status: the six minute walk test in chronic lung disease patients. Am J Respir Crit Care Med 1997;155:1278-82.

29. O'Donnell D, Lam M, Webb K. Spirometric correlates of improvement in exercise performance after anticholinergic therapy in chronic obstructive pulmonary disease. Am J Respir Crit Care Med 1999;160:542-9.

30. Puhan M, Mador $\mathbf{M}$, Held $\mathrm{U}$, et al. Interpretation of treatment changes in 6-minute walk distance in patients with COPD. Eur Respir J 2008;32:637-43.

31. Fujimoto K, Matsuzawa $Y$, Yamaguchi $S$, et al. Benefits of oxygen on exercise performance and pulmonary hemodynamics in patients with COPD with mild hypoxemia. Chest 2002;122:457-63. 